\title{
Factors Affecting the Academic Performance of Undergraduate Student Nurses
}

\author{
Khudija Mushtaq*, Muhammad Hussain, Muhammad Afzal, Syed Amir Gilani \\ Lahore School of Nursing, The University of Lahore, Lahore, Pakistan.
}

\begin{abstract}
Background: The nursing school undergraduates' performance influences the quality production of graduates. These in turn will be the future leaders and workforce for the country in improving the health care system. Thus it is imperative that the students do achieve good performance standards. Academic achievement or performance is the degree in which a learner, instructor or organization have accomplished their short term or long term learning objectives.
\end{abstract}

Objective: The main purpose of this study was to explore the factors (e.g., student related, school related, home related, teacher related) that may affect the academic performance of Undergraduate Nursing Students (UNSs).

Material and Methods: In this descriptive research study, a cross-sectional survey design was used to conduct this research study. Through simple random sampling technique, a sample of 129 Undergraduate Nursing Students was selected from the BSN (Bachelor of Science in Nursing) and Post RN BScN (Registered Nurse Bachelor of Science in Nursing) Students of the Lahore School of Nursing, The University of Lahore, Pakistan. A modified version [1] of the research scale was used to collect the relevant data from the research subjects.

Result: One hundred and twenty-nine student nurses participated in this research study; the majority of the participants were females 110 $(85.3 \%)$. Four types of factors such as teacher-related with an overall mean (3.90), school-related (3.88), student-related (3.83), and home-related factors (3.48) were studied to explore their effect on the academic performance of student nurses. It was found that teacher related factors were at the top with overall mean score of 3.90 and family-related factors were at the lowest level with an overall mean score of 3.48 .

Conclusion: The result shows that identified factors have influence on academic performance of student nurses. Finding can be used by administrators, educators and evaluators in designing and implementing an educational programs geared to developed academic performance among student nurses.

Keywords: Undergraduate nurses, Learners, Academic performance, Teacher-related factors, School-related factors, Student-related factors, Home-related factors.

\section{INTRODUCTION}

Numerous factors indicate a student's academic success. Academic performance is the degree to which a learner, teacher or institution has achieved his/her short or long term educational goals. Some graduates get top position while many may not graduate highest of their class, they may hold management positions in several student groups or mark high on standardized tests.

As nursing educators continue to redefine learning and assessment across the continuum, application of competency-based nursing education in the undergraduate setting has become a focus of many nursing schools [2]. Educators are challenged to find innovative teaching strategies to effectively prepare new graduates for entering the workforce [3].

Learners need to study efficiently and clear their examinations to graduate. Thus, educational improvement has turn out to be an important means for computing educational growth, and

*Address correspondence to this author at the Lahore School of Nursing, The University of Lahore, Lahore, Pakistan

E-mail: khudija79@gmail.com there is a necessity to examine the elements that distress it. The success of each learning organization is dignified by its educational performance or by how many learners come across the values set. Presently, academic failure of students is a spectacle of developing universal interest due to their financial effect and their destructive impact on the accessibility of forthcoming nurses in different healthcare organizations. The factors recognized as manipulating students' educational performance comprise the socio economic context of custodians; student's related factors such as study habits, school related such as education conveniences, appropriate assistance, domestic pressure, personality traits and also teaching skills [4].

Academic success is one of the main reasons examined or observed by nursing school administration during the appointment of facility specifically for the new graduates. Therefore, undergraduates must place maximum struggle in their learning to attain remarkable rankings and get themselves ready for upcoming employment opportunities meeting the demand of the employer [5].

Most of the earlier researches on students' academic 
performance concentrated on topic such as teaching abilities, classroom atmosphere, gender dissimilarity, teaching method, family motivation, historical and socio-economic factors [6]. student nurses are the next generation of practical nurses so, for this it is very important that they have to get quality of education through overcoming the identified factors [7].

Academic achievements of students can be assessed by their ability to comprehend text, lessons and practical skills and to produce them. This is the standard for judging the overall capabilities calculated by examination outcomes and also reflect the performance of teaching faculty. Student interest refers to the degree of attention, curiosity, attentiveness, optimism, and passion that students show when they are learning or being taught, which extends to the level of motivation they have to learn and progress in their education [8].

The academy is an important organization in coaching and transmission of awareness to learners as well as in the analysis, synthesis, creation and transmission of information with the help of educational practice. The results from the campus to the general public should be graduates with knowledge that have employments and are decent residents that will aid to improve the nation state as a defensible educated. The difficulty faced by educators in the earlier and today is the unsuitable learning performance of the learners as per student's interest, lack of study policies, and delivery of work in-time. Such unfortunate activities disturb educators in teaching and class room doings can't achieve their goals. Moreover, it upsets the learners and students will not capable to complete their study as imagine [5].

Research findings by Planning and Research department recommend that adverse attitudes toward education are due to deficiency of elementary expertise in learning, the inability to implement pedagogy, and poor self-efficacy that affect the success or failure of learners. Self-efficacy is the confidence that one has the skills to shape, design and carry-out the actions essential to handle situations at time. These views defined as key contributing factor of how public think, act and feel [9].

One of the maximum explored and discussed factor amongst the specialist instructors is the socio-economic situation, in addition to other reasons that contribute to the academic achievements of students. It has been commonly observed that socio-economic status of learners adversely affects their academic performance. Most of the educationists report that the low socio-economic situation has adverse impact on the learners' academic achievements; for the reason that basic necessities of the students remain defenseless and consequently do not achieve well in academic terms. It assures the acquisition of knowledge and the expertise that individuals make to increase their production and develop their value of lifespan. This upsurge in throughput as well leads to fresh sources of profitability that elevate the nation's financial development [10].

The question of low graded academic achievements of learners in evolving nations is of great alarm at all. In under developed states the difficulty of deprived academic achievement points to the broadly accepted reduced level of education. Government share in advanced learning and its productivity in terms of student success in students' worthy achievements have been observed to be uneven with public spending. Maximum of the under developed nation state are civilizing their structure in an attempt to enhance their participation in tertiary education [11].

The research described that bulk of the contributors were 4th year undergraduates seventy two (45\%), followed by 3 rd year sixty four $(40 \%)$ and 5 th year undergraduates twenty four $(15 \%)$. There were no major changes in the academic achievement of college and individual learners, those reading in the library or away from the public library and individuals who study at hours of daylight in relation to the night. Contrariwise, there were substantial variances in academic performance among learners with seventy five percent and above, and others with a participation rate of less than $75 \%$ [12].

A research accompanied by Moges Endalamaw Yigermal on students at the Arba Minch University Economic Campus shows that family-structure has extreme impact on the academic achievements of learners. In this research family earnings and educational stages of paternities as well as entry examination of learners define determine the achievement of the students in education. Undergraduates from uneducated parentages perform less than literate parents. This implies the socio-economic back ground of parents is an incentive for academic development and student performance [13].

According to this investigation school attendance is a vital reason in academic achievement of the students. The participation rate is 0.471 . Consistent students have good grades, keeping all other variable persistent. This outcome is the similar and who found that participation had a constructive and significant impact on academic achievement. Gardy \& AKBAY report that low attendance is related to reduce academic performance. Universities or colleges are social institutes in which clusters of people are assembled to participate to educational practices and such interaction can create positive or negative influences for people [10].

This study demonstrated that there was a considerably higher quantity of women who participated in the GPA system eighty five percent vs. fifty nine percent; $(p<0.01)$. This great variance in gender ratios among the binary evaluation systems and may be a conceivable cause why we saw advanced levels of stress test and apparent stress in the GPA system compared 
to the pass or fail method. Conversely, it would be observed that medical colleges or universities in Pakistan commonly have a greater proportion of students; therefore this provides an added exact demonstration of the student nurses population in the nursing college's crossways to the country. Certain researches have correlated female gender with stress in learners [14].

This study recommends that the students' grade was positive and is closely related to high school and grades. In addition, mother's level of education has also been positively interconnected with students' academic achievements. The students grades was negative and is closely related to class, age, extra-curricular activities, and student participation in the discussions and responding to the exercise [15].

The Socio economic situation of undergraduates influence the excellence of their cognitive and physical health which in result affects their academic achievement [15].

The investigation discovered that learners with economic difficulties have reduced educational performance for the reason that they could not buy pre-determined academic material; their elementary necessities were not met. Food insecurity due to the low socio-economic status associated with the lowest level of student, average, indirect and directly, due to poor mental health. such outcomes support the requirement of upcoming interventions and rule on significance of giving undergraduates with elementary requirements to be successful equally educationally and also in future [16].

Alshammari et al. stated that entire factors related to the learner, institute, home and instructor significantly affect the academic performance of the learner. The outcomes additionally showed that amongst the four factors data, educator associated factors has highest influence on academic achievement as indicated by the average of 4.16. Further shows that participants considered that teaching approaches; student tutoring and communication obstacle hamper their academicals performance. There are numerous issues that greatly influence students' academic performance; tutor associated factors are at the topmost in the list. This means that lecturers play most important part in the performance of the student and consequently are really accountable for good or bad learner achievement [1].

The main function for the teachers is to teach their students more efficiently and effectively to be able to demonstrate excellent performance. In order to achieve this goal, it is necessary for the teachers to better understand the factors that may contribute to the students' academic achievement [17].

According to the research estimates, Out of the entire fifteen participants, ninety three percent of the Directors approved that natural value materials create learners perform. In addition, he advised the lecturer to constantly deliver education of learning resources to improve the students' academic achievement. On the other hand, the accessibility and acceptance of teaching and learning materials is not sufficient [18].

\section{Aims of the Study}

To study the factors (e.g., student related, school related, home related, teacher related) that may affect the academic performance of Undergraduate Nursing Students (UNSs) at the Lahore School of Nursing, The University of Lahore, Pakistan.

\section{Significance of the Study}

The study was significant for professional learners, teachers, decision makers or policy makers who worked on minimizing the factors which affect seriously affecting academic performance of learners. This research may also contribute to the management of school of Nursing to consider when formulating strategies to increase the academic performance and value of schooling by altering the students attitude on the way to education through conducting seminars, workshops, conferences, parents meeting, and financial supporter's NGO (Non-Governmental Organization) about elimination of influencing factors.

\section{Hypothesis}

There is no existing difference in the extent of the identified factors that affect the academic performance of nursing student when their profile is measured.

\section{METHODS}

\section{Setting}

The setting for this research study was Lahore School of Nursing, The University of Lahore.

\section{Research Design}

A cross-sectional survey design was used to conduct this descriptive research study.

\section{Population}

The population of this was comprised of all student nurses of two years Post RN Bachelor of Science and four years BS Nurses, Lahore School of Nursing, The University of Lahore, Pakistan.

\section{Sampling}

Simple random sampling technique was used to obtain sample in this research study. A sample $\mathrm{n}=129$ was recruited from the targeted population (BSN and Post RN BScN Students).

\section{Research Instrument}

A well-structured and adopted questionnaire was used after 
getting permission from the author in order to collect the data from the participants. Questionnaire was divided into two parts. Part one was associated with demographic profile having seven questions and second part was related to four factors that are Students related (interest and study habits), School related (learning facilities), Home related (proper guidance and family stress) and Teacher related (personality traits and teaching skills). The questionnaire contains 40 questions based on 5-point Likert scale where 5 means always, 4 means often, 3 means sometimes, 2 means rarely and 1 means never [1].

\section{RESULTS}

\section{Profile of the Respondents}

Table 1. Demographic Data Result.

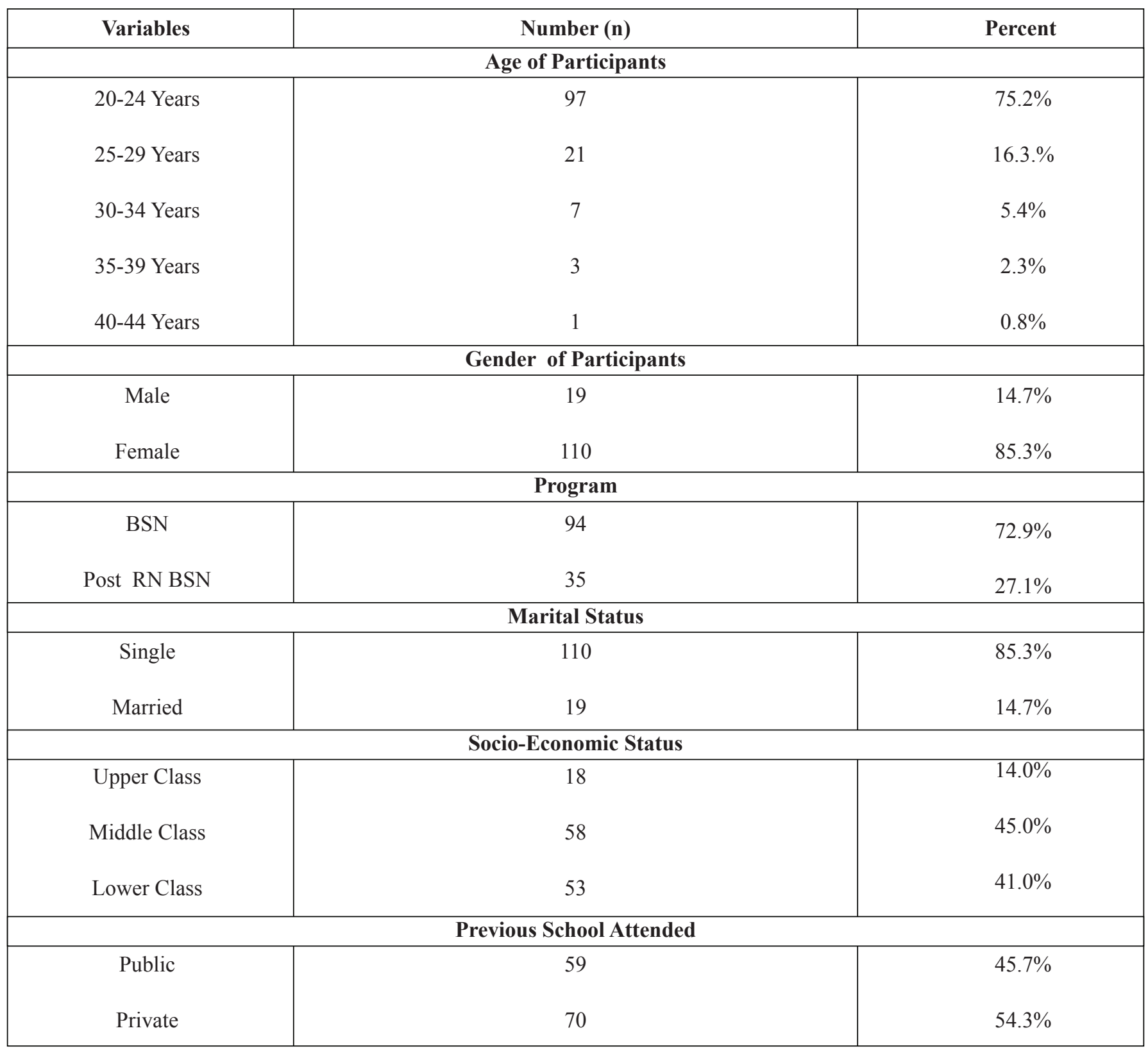

Table 1 shows that $110(85.3 \%)$ of the respondents' were female and $19(14.7 \%)$ were male. Among $\mathrm{n}=129$ participants 97 (75.2\%) were between 20-24years, 21 (16.3\%) with the mean of twenty two. An entire of 94 (72.9\%) participants were from BSN program but 35 (27.1\%) were in the post RN BSN. Majority $110(85.3 \%)$ of the participants were single and only $19(14.7 \%)$ were married. The 58 $(45.0 \%)$ participants belongs to the middle class and most of the participants $70(54.3 \%)$ were educated in private school. 
Table 2. Students Related Factors.

\begin{tabular}{|c|c|c|c|}
\hline & Variables & Mean & Remarks \\
\hline 1. & How good did you pay attention to your instructor? & 4.09 & Extensive \\
\hline 2. & How good do you want to acquire worthy scores on quiz, tests projects and tasks or assignments? & 3.89 & Extensive \\
\hline 3. & $\begin{array}{l}\text { How good you truly contribute in the conversation, responding to exercises and clearing stuffs } \\
\text { that you do not understand? }\end{array}$ & 4.09 & Extensive \\
\hline 4. & How good did you make me ready for substance? & 4.14 & Extensive \\
\hline 5. & $\begin{array}{l}\text { How good did you become upset when dialogue or discussion is disturbed or the instructor is } \\
\text { absent? }\end{array}$ & 3.58 & Extensive \\
\hline 6. & How good did you apply struggle when you have to do problematic assignment? & 3.90 & Extensive \\
\hline 7. & How good did you learning the lesson you lost if you were not present in the class? & 3.72 & Extensive \\
\hline 8. & How good did you reading and get ready for test and quiz? & 4.11 & Extensive \\
\hline 9. & How good did you perceive to it that extra curriculum activities did not hinder your studies? & 3.62 & Extensive \\
\hline 10 & How good did you have particular residence for reading at home that you kept neat and arranged? & 3.81 & Extensive \\
\hline 11. & How good did you fix your task on a regular basis? & 3.86 & Extensive \\
\hline 12 & How good did you use your free time in doing project or learning your lesson? & 3.58 & Extensive \\
\hline 13. & $\begin{array}{l}\text { How good did you study tougher to increase your performance; when you acquire minimum } \\
\text { scores? }\end{array}$ & 3.92 & Extensive \\
\hline 14. & $\begin{array}{l}\text { How good did you use a smaller amount of time with friends for the school-days to focus even } \\
\text { more on your study? }\end{array}$ & 3.50 & Extensive \\
\hline \multirow[t]{2}{*}{15.} & $\begin{array}{l}\text { How good did you have a preference in completing your studies and your projects before seeing } \\
\text { any TV program? }\end{array}$ & 3.66 & Extensive \\
\hline & Overall Mean & 3.83 & \\
\hline
\end{tabular}

Table 2 displays Student related barriers that affect their academic performance with the grand mean of 3.88 . Respondents answer to a question 'how good did you read and get prepared your quiz /tests, 04(3.0\%) responded in never, $04(3.0 \%)$ rarely, $24(17.9 \%)$ were answer in sometimes, $39(29.1 \%)$ replayed in often and 58(43.3\%) were answered in always with mean \& SD 4.11+1.02. On replying question 'how you handle that extra-curricular activity did not hinder your study, 07(5.2\%) responded in never, $15(11.2 \%)$ rarely,
$30(22.4 \%)$ were responded in sometimes, 45(33.6\%) answered in often and 32(23.9\%) were replied in always with mean \& SD 3.62+1.14 On a question 'how well did you wish to acquire valuable scores in assignment, quiz and projects, $05(3.7 \%)$ participants mentioned in never, 05(3.7\%) participants mentioned rarely, 21(15.4\%) were stated in sometimes, 38(28.4\%) respondents stated in often and $58(43.3 \%)$ were answered in always with mean \& SD $3.89+1.07$.

Table 3. School Related Factors.

\begin{tabular}{|c|c|c|c|}
\hline & Variables & Mean & Remarks \\
\hline 1. & $\begin{array}{l}\text { How well do you use the learning facilities provided by the university (library, computer lab, } \\
\text { whiteboard? }\end{array}$ & 3.94 & Extensive \\
\hline 2. & How well do you use the learning facilities in performing your course work? & 3.96 & Extensive \\
\hline 3. & $\begin{array}{l}\text { How well do you think the facilities provided by the university meet the standards for physical } \\
\text { requirement (classroom size, lighting, air conditioning, tables and chairs? }\end{array}$ & 4.01 & Extensive \\
\hline 4. & How well do you can easily access the internet in the library? & 3.86 & Extensive \\
\hline \multirow[t]{2}{*}{5.} & How well do you adhere to the "Speak English" of the university? & 3.58 & Extensive \\
\hline & Overall Mean & 3.88 & \\
\hline
\end{tabular}

Table 3 displays School related issues that affect the academic performance of undergraduate nurses with the grand mean of 3.88. Outcomes of the study disclose on asking a question that "how easily you can access the facility of internet in the university library" Among the participants $(\mathrm{n}=129)$, $04(3.0 \%)$ mentioned never, $10(7.5 \%)$ mentioned rarely,
$29(21.6 \%)$ were stated sometimes, 43(32.1\%) mentioned in often and $43(32.1 \%)$ were replied in always with mean \& SD $3.86+1.10$. In reply to one more question "How good did you observe with the "speak English policy of the college", the contributors replied as below. $8(6.0 \%)$ stated in never, $17(12.7 \%)$ stated rarely,. 26(19.4\%) were stated in 
sometimes, 48(35.8\%) mentioned often and 30(22.4\%) were responded in always with $3.56+1.21$. On inquiring "how good did you use the learning facilities that are given by the college' $07(5.2 \%)$ responded in never, $10(7.5 \%)$ rarely,
$23(17.2 \%)$ were answer in sometimes, 32(23.9\%) replayed in often and 56(41.8\%) were answered in always with mean \& SD $3.94+1.20$.

Table 4. Home-Related Dynamics.

\begin{tabular}{|c|l|c|c|}
\hline \multicolumn{1}{|c|}{ Variables } & Mean & Remarks \\
\hline 1. & Are you motivated by your parents to improve your studies? & 4.26 & Extensive \\
\hline 2. & Do you use your learning materials (books, dictionary, and laptop) suitable for your study? & 4.03 & Extensive \\
\hline 3. & Do you have tutorial session after class? & 3.33 & Moderate \\
\hline 4. & Do your parents help you in your homework? & 3.42 & Moderate \\
\hline 5. & Do you ask guidance from your elders and /or family? & 3.43 & Moderate \\
\hline 6. & Do you easily distracted by your friends? & 3.23 & Moderate \\
\hline 7. & Do you do too many house hold chores? & 3.31 & Moderate \\
\hline 8. & Do you get disturbed by your siblings? & 3.11 & Moderate \\
\hline 9. & Do your mobile phone/ Television/Radio/gadgets distract you while studying your lesion? & 3.59 & Extensive \\
\hline 10. & Do your family experience financial problem? & 3.15 & Moderate \\
\hline & \multicolumn{1}{|c}{ Overall Mean } & 3.48 & \\
\hline
\end{tabular}

Table 4 shows home-related problems that affect the academic performance of undergraduate nurses with the overall mean of 3.84 .

In discussing the Home related Issues with feature where researcher asked 'got disturbance by students siblings',

Table 5. Teacher-Related Dynamics.

\begin{tabular}{|l|l|c|c|}
\hline \multicolumn{1}{|c|}{ Variables } & Mean & Remarks \\
\hline 1. & Do your instructors have a worthy association with the learners and colleagues? & 4.14 & Extensive \\
\hline 2. & $\begin{array}{l}\text { Do your instructors execute appropriate discipline and are not merciful in ensuing the recom- } \\
\text { mended rules? }\end{array}$ & 3.96 & Extensive \\
\hline 3. & Do your instructors expose to ideas, views and worthy of praise? & 3.88 & Extensive \\
\hline 4. & Did your instructors show intelligence, confidence and stability in making-decision? & 3.84 & Extensive \\
\hline 5. & Did your instructors have an attractive personality with good-sense of humor? & 3.87 & Extensive \\
\hline 6. & Did your instructors clarify the objectives of the lesson openly at the start of every lecture? & 4.04 & Extensive \\
\hline 7. & Did your instructors have mastery of topic material? & 3.81 & Extensive \\
\hline 8. & Did your instructor prepare the presentation of the object by following the organized routine? & 3.86 & Extensive \\
\hline 9. & Did your teachers have well-run with current leaning related to the subject material? & 3.81 & Extensive \\
\hline 10 & $\begin{array}{l}\text { Did your teachers demonstrate several strategies; teaching devices/ aids and methods in present- } \\
\text { ing lesson? }\end{array}$ & 3.86 & Extensive \\
\hline & \multicolumn{1}{|c|}{ Overall Mean } & 3.90 & \\
\hline
\end{tabular}

Table 5 shows teacher-related problems that affect the academic performance of undergraduate nurses with the grand mean of 3.90. In discussing the teacher Connected Issues with feature where researcher asked in factor one 'my instructors have worthy relation-ship with students and also colleagues as well' and on question number six where researcher asked 'Teachers explain all the lesson objectives openly at the beginning of every lecture' having the highest mean score respectively. another reason (intimate experience financial problem) and factor 6 (Disturbed by my friends) abstaining lower most mean outcome which have $3.11,3.15$ and 3.23 respectively.
The result shows that the teacher's performance plays a major role in the student's academic life and further shows that the interviewed student was of great importance to the mastery of the teachers, to learning and to support them with their learners. On the other hand, where participants identify their parents as a source of inspiration, motivation is main key to learning. Academic assistance received by parents is relatively narrow, as shown by the average of 3.33, 3.42, 3.43, 3.23, $3.31,3.11$ and 3.15 for data $3,4,5,6,7,8$ and 10 . 
Table 6. Four Factors.

\begin{tabular}{|c|l|c|l|}
\hline & \multicolumn{1}{|c|}{ Factors } & Overall Mean & Remarks \\
\hline 1. & Student related factors & 3.83 & Extensive \\
\hline 2. & School related factors & 3.88 & Extensive \\
\hline 3. & Home related factors & 3.48 & Moderate \\
\hline 4. & Teacher related factors & 3.90 & Extensive \\
\hline
\end{tabular}

Note: 1.00 to 1.50 shows never or Very Low Level; 1.51 to 2.50 indicates Rarely or Low Level; 2.51 to 3.50 displays sometimes or moderate level 3.51 to 4.50 displays Often or Extensive; 4.51 to 5.00 shows Always or highly Extensive.

Table 6 shows that the trainer-related factors are in the highest grade with an average of 3.90, and the factors associated with the institute are in the second step with an average of 3.88 . The dynamics associated with the undergraduate are at the third level with an average of 3.83 and the family-related factors are at the lowest level of the mean age of 3.48.

\section{DISCUSSION}

There are several factors that contribute to the quality of academic performance of undergraduate students. Current study focused on some of the factors that may affect the students' academic performance.

The findings from the current study reveal that all the factors concerning the student, the school, the home and the teacher have a significant positive effect on the academic performance of the students. The results further reveal that amongst the all four factors, teacher related factors have the highest influence on the academic performance as shown by the mean of 3.90. Moreover, this study shows that participants perceived that teaching approaches, learners relationships with their instructors and the communication-barrier impeded their academic performance. In this way, there is need for instructors and learners to sit together; discuss their opportunities, trust and mutually improve approaches that will enhance the learners' achievements.

This supports the outcome of the study carried out by Alos and his colleagues shows that amongst the various factors that significantly affect students' academic performance; teacher related factors are at the top of the list. This means that instructors plays important role in the academic performance of the students and consequently are very accountable for reduced or extensive performance of the students [5].

Research conducted by Alshammari and colleagues in 2017 shows that all factors (e.g., home, school, teacher, students) extensively influence the academic-performance of the students. The results further revealed that among the entire factors, instructor related factors have highest influence on the academic performance, as specified by the average mean of 4.16. Home related factors had the moderate effect on the academic performance of undergraduate student nurses when answering a question "Do you distract easily by your friends" with the lowest mean value of 3.54 .

Current research study also revealed the similar extensive impact on the participant's academic-performance, as showed by an average mean of 3.90, apart from home-related factors having moderate impact on academic performance by grand mean 3.48 .

Reduced performance in the course is similarly affected by the school related dynamics. A result of this study determines that most of the attendees were responded to the usage of learning facilities delivered by the school or university,(1).7\% respondents were answered in never, (23) $17.2 \%$ were answered in some times, (60)44.8\% were responded in often with mean of 3.94. School associated dynamics have been displayed an extended influence on the student nurses academic achievement. Such features include the accessibility and the actual value of learning-facilities e.g. computer, library, research laboratory as well as academic strategies applied by the institution of higher education. Institutes with lacking of elementary services and assets such as recommended text books may have reduced academic-performance.

According to Owoeye and Yara the key purpose of a university library is to have all the records and books, journals and additional needed resources accessible to the learners. They moreover showed that university or school libraries may not be useful if available books are not acceptable and latest. The library must have calm atmosphere and must be rich in literature with sufficient books, and other learning assistances that can aid the learner to achieve well and students may require adequate space for their learning so they did not require crushing themselves collected.

Undergraduate achieves more when they are prepared and willing to study and when they identify the purpose and need of education. It happened only when learner agrees upon those objectives; so learner becomes added energetic, more serious and better systematized in chasing of preset objectives.

In current study among the student related factors, the uppermost digit were given to how well do you listen to your instructor with mean and SD (4.09+.962), how sufficiently did you actually participate in the class room discussion and clarifying the objectives with mean and SD (3.89+.962), how well did you prepare your subject with the highest Mean and SD (4.11+949), exerting effort with the difficult assignment with mean and SD $(3.90+1.07)$.

In another previous study according to Kumar and Singh many learners increase positive-attitude on the way to their individual studies. They get ready themselves for matter, test, exam and dialogues. They energetically contribute in 
interrogative and responding exercises and acquire valuable scores on exams, tests, projects and assignments [19].

In current study results displayed that home related dynamics have moderate influence on the undergraduate nurse's academic performance when answering to a question did you get distracted by your relatives with the lowest mean value of 3.11, did your family have faced any economic problems with the mean value of 3.15, Did you easily distracted by your friends with the mean of 3.23. In spite of its position on the list of all factors; obviously, home related factor quiet has broad influence on the participant's academic performance with the grand mean of 3.48.

This study denoted that home backing plays a dynamic part in the accomplishment of learners. Many Other researchers such as Evans and associates, [1] noted the similar result regarding the impact of home related factor on the academic performance of students, suggest that deficiency of backing from home leads to failure in the learners academic performance.

Moreover, financial status of the learners distresses the excellence of their cognitive and physical health which in result affects students' academic achievement. An investigation by Farooq and friends exposed that learners with economic difficulties have a reduced academic performance for the reason that they cannot have enough money to buy recommended books and their basic requirements remain incomplete.

\section{LIMITATIONS}

There are certain limitations of this study.

- The sample size was very small that was comprised of only 129 research subjects.

- This study was conducted only in one private institute i.e. Lahore School of Nursing, Lahore.

- The study was included only four factors other relative factors that affect the academic performance can be identified and result might be improved than existing study.

\section{CONCLUSION}

It can be concluded that the students' academic performance is influenced by outer aspects e.g., teaching and learning-related factors; inadequate assets, deficiency of school accommodation, study-related aspects and socio-economic issues and inner aspects such as learner attitudes, deficiency of self-control.

An interventional program must be sensibly designed and applied by the managers and the faculty of the school. Evaluation must consist of learner's time-management abilities; study abilities, anxiety managing abilities, student hospitality and nursing expectations, student's family responsibilities, access in the student's technology and activities outside the school.

This evaluation can help teachers to provide more support to students so that they can develop effective curriculum and finish their study within a defined timeframe [20]. This intervention program aims to improve the academic performance of student nurses and eventually their lives.

\section{CONFLICT OF INTEREST}

Declared none.

\section{ACKNOWLEDGEMENTS}

This research work was not possible without the help and encouragement of many individuals to whom I am really very grateful. First and foremost, I would like to thank Mr. Muhammad Afzal (The Principal of Lahore School of Nursing) who allowed me for this study. Sir Muhammad Hussain for being my supervisor and for being the greatest inspiration for my work when I had no idea to perform a research work, and who has been supportive and encouraging me throughout the whole process and also thankful to my family, parents and classfellows.

Secondly I would also like to thank my parents and friends who helped me a lot in finalizing this project within the limited time frame.

\section{REFERENCES}

[1] Alshammari F, Saguban R, Pasay-an E, Altheban A, Al-Shammari L. Factors affecting the academic performance of student nurses: A cross-sectional study. J Nurs Educ Pract 2017; 8(1): 60. DOI: 10.5430/jnep.v8n1p60

[2] Fazio SB, Ledford CH, Aronowitz PB, et al. Competency-based medical education in the internal medicine clerkship: A report from the Alliance for academic internal medicine undergraduate medical education task force. Acad Med 2018; 93(3): 421-7. DOI: 10.1097/ACM.0000000000001896

[3] Robinson BK. Dearmon V, Evidence-based nursing education: Effective use of instructional design and simulated learning environments to enhance knowledge transfer in undergraduate nursing students. J Prof Nurs 2013; 29(4): 203-9. DOI: 10.1016/j.profnurs.2012.04.022

[4] Varachanon P. Study of learning behaviors of nursing student at the royal thai navy college of nursing. Procedia Soc Behav Sci 2015; 197: 1043-7. DOI: 10.1016/j.sbspro.2015.07.313

[5] Alos SB, Caranto LC, David JJT. Factors affecting the academic performance of the student nurses of BSU. Int J Nurs Sci 2015; 5(2): 60-5. 
[6] Singh S, Malik S, Singh P. Factors affecting academic performance of students. Paripex-Indian J Res 2016; 5(4): 176-8.

[7] Mushtaq I, Khan SN. Factors affecting students academic performance. Global J Manag Bus Res 2012; 12(9): Version 1.0 .

[8] Skinner EA, Belmont MJ. Motivation in the classroom: Reciprocal effects of teacher behavior and student engagement across the school year. Educ Psychol 1993; 85(4): 571. DOI: $10.1037 / 0022-0663.85 .4 .571$

[9] Md Nordin S, Fatimah W, Ahmad WFW, Nayan MY. A Conceptual framework in examining the contributing factors to low academic achievement: Self-efficacy, cognitive ability, support system and socio-economic. In: International Conference On Management, Social Sciences And Humanities 2012.

[10] Gardy I, Akbay C. Academic performance of undergraduate students at Soran university in Northern Iraq. IJARET 2015; 2(4): 92-7.

[11] Yigermal ME. The Determinants of academic performance of under graduate students: In the case of Arba Minch University chamo campus. Adv Sci Hum 2017; 3(4): 35-42. DOI: 10.11648/j.ash.20170304.12

[12] Ella R, Akpabio I, Samson-Akpan P. Influence of study habits on undergraduate nursing students academic performance in University of Calabar, Nigeria. Am Res J Nurs 2015; 1(3): 1-6.

[13] Yigermal ME. Determinant of Academic Performance of Under Graduate Students: In the Cause of Arba Minch University Chamo Campus. J Educ Pract 2017; 8(10): 155-66.

[14] Ali M, Asim H, Edhi AL, et al. Does academic assessment system type affect levels of academic stress in medical students? A cross-sectional study from Pakistan. Med Educ Online 2015; 20(1): 27706. DOI: 10.3402/meo.v20.27706

[15] Tom F, Coetzee I, Heyns T. Factors influencing academic performance in biological sciences among students in a nursing education institution in the Eastern Cape Province: An appreciative inquiry approach: nursing curricular issues. Afr J Phys Health Educ Recreat Dance 2014; 20(Supple 3): 102-15.

[16] Martinez SM, Frongillo EA, Leung C, Ritchie L. No food for thought: Food insecurity is related to poor mental health and lower academic performance among students in California's public university system. J Health Psychol 2018; 1: 359105318783028. [Epub ahead of print].

DOI: $10.1177 / 1359105318783028$

[17] Farooq MS, Chaudhry AH, Shafiq M, Berhanu G. Factors affecting students' quality of academic performance: A case of secondary school level. J Quality Technol Manag 2011; 7(2): $1-14$.

[18] Wanyama EG, Simatwa EM, Okwach TO. Contribution of school administrators to teaching enhancement of students'academic performance in secondary schools in kenya: An empirical study across secondary schools of Emuhaya and Vihiga sub-counties. Int J Curr Res 2018; 10(3): 67302-14.

[19] Kumar A, Singh A. A review on Alzheimer's disease pathophysiology and its management: An update. Pharmacol Rep 2015; 67(2): 195-203. DOI: 10.1016/j.pharep.2014.09.004

[20] Pinehas LN, Mulenga E, Amadhila J. Factors that hinder the academic performance of the nursing students who registered as first years in 2010 at the University of Namibia (UNAM), Oshakati Campus in Oshana, Namibia. J Nurs Educ Pract 2017; 7(8): 63. DOI: 10.5430/jnep.v7n8p63 